\title{
Concise Review: Knee Cartilage Repair Techniques using Cellular Therapy
}

\author{
Coursier $\mathbf{R}^{1,2}$, Mazor $\mathbf{M}^{1}$, Best $\mathbf{T M}^{4}$, Lespessailles $\mathrm{E}^{1,3}$ and Toumi $\mathbf{H}^{* 1,3}$ \\ ${ }^{1}$ Treatment and Prevention of Osteoporosis, University of Orleans, France \\ ${ }^{2}$ Department of Orthopaedic Surgery, Hospital Group of the Catholic Institute of Lille (GHICL), France \\ ${ }^{3}$ Rheumatology Service, Orléans Regional Hospital Center, France \\ ${ }^{4}$ UHealth Sports Medicine Institute, University of Miami Miller School of Medicine, USA
}

Received: June 07,2018; Published: June 14, 2018

*Corresponding author: Hechmi Toumi, Vice-Director Laboratory EA-I3MTO, University of Orléans, Vice-President of the Institute of Research, Treatment and Prevention of Osteoporosis, CHR d'Orléans, France

\begin{abstract}
Osteoarthritis is a degenerative disease of joints and leading cause of joint pain resulting from subchondral bone hypertrophy and inflammation. Although, many researches have been focused to overcome the articular cartilage, the latter has proven to be a very difficult tissue to repair defeating researchers, surgeons, and patients. Numerous surgical techniques have been developed to address focal cartilage defects. One area that seems encouraging is cell-based therapies based on stem cells to promote cartilage repair. Several human body tissues contain mesenchymal stem cells from where these can be harvested and cultured. This review summarises autologous chondrocytes implantation, first generation, second generation, third generation and recent clinical trials on mesenchymal stem cells implantation.
\end{abstract}

Keywords: Osteoarthritis; Cartilage; Chondrocytes Implantation; Mesenchymal Stem Cells

\section{Introduction}

Articular hyaline cartilage is a tissue whose mechanical properties allow joint movements with a low coefficient of friction and a high absorption of constraints. Degradation of hyaline cartilage causes functional impairment of the joint, pain and decreased quality of life. In the case of isolated cartilage lesion of the knee, a remedy that allows histological restoration of cartilage and therefore a functional improvement for the long-term represents a therapeutic challenge. The hyaline cartilage is organized into four distinct layers. It is a non-vascularised and non-innervated tissue [1] composed of chondrocytes, which come from the undifferentiated mesenchymal stem cells, immersed in an extracellular matrix. This matrix synthesized by chondrocytes consists mainly of water, electrolytes, collagen (type II mainly, IX and XI), proteoglycans (aggrecan) and glycoproteins. Production of the extracellular matrix is a function of various parameters such as growth factors, intra-articular mechanical stress, hormones or age.

Nutrition of articular cartilage occurs by soaking in the joint fluid but also by capillary from the adjacent connective tissues. Surgery offers many other restorative procedures with the objective of restoring joint function thanks to the return of a hyaline cartilage. The procedure chosen will depend on the size of the lesion, its depth, the age of the patient, the nature of the symptoms and the treatment authorization in each country. The therapeutic tools can be separated into three major groups; those conducting subchondral stimulation (Pridie, microfractures), reconstruction techniques which transplant mature cartilage (OATS: osteochondral autologous transfer surgery, allograft) and finally cellular transplants which aim to create a favourable environment for cartilage healing. The aim of this literature review is to identify all surgical possibilities used to repair articular cartilage of the knee using cellular transplant with or without culture. The main principles of these techniques will be reviewed in the light of articles and the most recent results which will be compared and evaluated.

\section{Autologous Chondrocyte Implantation}

Since 1994, Brittberg [2] has paved the way for transplantation of chondrocytes (ACI/T: Autologous Chondrocyte Implantation/ Transplantation) to treat osteochondral lesions. Currently we can describe 3 generations of chondrocytes graft. 


\section{a) First generation: C1G}

The criteria permitting us to consider transplantation of chondrocytes as first generation [3] are: a surgical procedure in two stages and chondrocytes coverage implanted by the periosteum or a collagen membrane. First generation chondrocyte grafts can be divided into ACIp (cover by periosteal) and ACIc (cover by a derivative of collagen). Brittberg [2] describes a cell culture from 11 to 21 days, conducted through collected chondrocytes on healthy cartilage from the medial condyle with two surgical procedures where the second consists in grafting cultured chondrocytes. To do this, an arthrotomy is again practiced; the cartilage lesion is heightened and the graft is placed at the bottom of the lesion. A coverage is ensured by the tibial periosteal taken from the patient and sutured above the graft. Viste [4] uses fibrin on the edges of the suture to avoid leakage of implanted cells. This practice requires a mastery of cell culture which is expensive but also two surgical procedures. The initiators of this technique [5] reported the fate of 224 patients to 12.8 years follow-up.

All assessed clinical scores are improved and 92\% of patients stated they were ready to undergo the same procedure if necessary. Clinical improvement is progressing over time without renewed negative impact related to the size of the lesion or age. Peterson [5] conclude that this technique is permanently effective for large osteochondral lesions isolated in the knee; Viste [4] and Moradi [6] have also highlighted good functional results at 6 and 10 years post procedure but they underline however that the best results are in younger patients who have a small size lesion since a short time. They also point to the continuing improvement of symptoms 1 year after surgery. However, this is as level IV without histological evaluation studies. These results are sometimes contested. Horas [7] showed that clinical outcomes were significantly better after OATS rather than after transplants of chondrocytes in 2 years of post procedure. The author conducted a histological analysis of transplant tissue and found after biopsies of the OATS group one aspect of hyaline type while for the ACI, it is the beaches of fibrocartilage.

Yet in another comparative study, after 10 years follow-up, Bentley [8], on 100 randomized patients revealed a very significant difference in favour of the ACI over the OATS. Conversely, Knutsen [9], who likened the ACI to microfractures found good clinical results in both groups but did not detect a significant difference between the 2 techniques after 5 years of follow-up. He tells even $5 \%$ failure rate with the ACIp (against 2.5\% for the microfractures) due to hypertrophy of the periosteum. It has also been shown that the first generation ACI give less good results when they are not used as first line therapy; indeed, after stimulation of the sub-chondral or microfractures, recourse to the ACIp offers inferior results according to Pestka [10] and Minas [11] that during a first-time treatment. Minas [12] resumed with a series of 210 patients who had received an ACIp with an average decline after 10 years. The survival of the ACIp is $71 \%$ in his long decline series but it still reports $25 \%$ failure rate which includes mainly delamination.

Despite this, the ACI's first generation can be used reliably and yields good results in the long term according to the author. It re- ported better results in young patients who have a single lesion of the knee, have the least possible recoil and whom the least surgeries were performed on the knee. With regard to age, Niemeyer [13] in a study of level II, doesn't highlight however best results in the group of patients under 40 years versus the group of patients over 40 years. Rosenberger [14] had already found similar results and felt that the reasons for the failures of the ACIp rates were similar before and after 45 years of age. In the therapeutic arsenal of cartilage lesions of the knee, it seems that a large initial lesion is a criterion for use ACI. Indeed, even in the event of fairly extensive injury (average $6.4 \mathrm{~cm}^{2}$ ), the ACIp can for referral to improve knee function and relieve the patient at 7.6 years follow-up according to Gillogly [15]. However, the analysis of his series is questionable because all the patients had a translation of the anterior tibial tuberosity and a $16 \%$ trochleoplasty and $33 \%$ of transplants were complicated periosteal hypertrophy. Concerning the location of the treated lesion, Trinh [16] shows that the ACIp improved patellofemoral function in the event of cartilage injury to the patella. However, the improvement is significantly higher than if a patellofemoral osteotomy is associated. It has even been shown that women had poorer outcomes than men with ACI's first generation of patella transplant [17].

The failures of the first generation ACI are mainly associated with periosteal hypertrophy or delamination of the cartilage [3,9,12\&15]. Harris [3] even found significant differences between different generations of ACI $7.7 \%$ of failures for the ACI with periosteal flap against $3.3 \%$ of second generation ACI). To avoid complications associated with the Brittberg technique and attributed to periosteum, autologous chondrocyte implantations have been developed under a synthetic membrane. This artificial membrane replaces the periosteum and fills the same function as the periosteum (remember the graft, to limit hemarthrosis). Covered chondrocyte grafts of a synthetic membrane (ACIc) are also called 1st generation. The membrane used is often derived from porcine collagen types I and III. Its use was justified by a desire to be less aggressive surgically and also because it has been shown that the periosteum covering the graft caused a hypertrophy and a cartilaginous delamination. Gooding [18] first, in a comparative study, highlighted the differences of clinical and histological findings in favour of synthetic rather than the periosteum membrane and complication rates were lower in the case of the use of pig membranes. Samuelson [19] showed that the ACIc? were slightly more profitable than the ACIp; he is interested in the economic part of the treatment and which has highlighted an additional cost due to follow-up operations in the case of coverage by the periosteum. The use of a synthetic membrane has emerged as a preferred alternative; however Pietschmann [20] showed in a comparative study that covered ACI periosteum or a synthetic membrane was accompanied in a similar way to hypertrophy of the graft. However, if a synthetic membrane is used, the hypertrophy tends to disappear.

From 2001, Dell' Acció [21] introduced a new concept for the first generation ACI: molecular markers of human chondrocytes. Saris [22] uses these chondrocytes which are selected by calculating the potential chondrogenic score of cells collected by markers and witnesses to the preservation of the phenotypic differentiation 
and maturation of these cells. The use of these selected chondrocytes (from first generation) was compared with some microfractures in a level I study. This method of selecting chondrocytes brings better clinical results [22] than the microfracture by 36 months of follow-up. Vanlauwe [23] with 5 years follow-up, finds that there's no superiority of one technique over another but that the failure occurs earlier in the case of patients treated with microfracture. It also concludes that the long delay between the onset of symptoms and surgical support is a factor aggravating the clinical outcome. First generation ACI remains for many authors a future treatment for treating deep cartilage lesions of moderate to high size. All the injured articular surfaces of the knee may benefit from this technique and advanced age permit treatment processing.

\section{b) Second Generation: C2G}

Second generation chondrocytes implantation has been developed from the beginning of the year 2000 to try to solve the problems encountered with first generation or procedures. Rather than re-siting the cultured chondrocytes the cartilage injury in vitro and then covering with a cloth, cartilage cells are cultured directly within a structure that is, the same, and implanted on the pathological area. Harris [3] states that second-generation transplants are still made in 2 ways (arthroscopic or arthrotomy) with implantation of chondrocytes cultivated and planted in a bio-absorbable matrix. There are many varieties of tissues able to 'receive' cultured chondrocytes. Kon [24] has listed in 2008 the nature of the available structures. These tissues may be "simple" membranes or from scaffold in 3 dimensions. The advantage of 3D structures is to allow the continuation of the phenotypic differentiation of chondrocytes [25] but also to fill an osteochondral defect. The matrices must be biocompatible and biodegradable.

The nature of the fabrics used varies and can be found in the literature of synthetic tissues and natural proteins (collagen type I, III, fibrin gel) [26-31] or polysaccharide (alginate agarose, hyaluronic acid) [32,33]. Some fabrics offer the possibility of a primary fixation without suture, allowing all arthroscopic [34].

Most have been evaluated scientifically however some techniques have not been authorized for the market in Europe or in the US which limits the evaluations and comparisons to non-investigative teams. The main second generation chondrocyte transplants are listed below. The MACI $($ (Matrix Autologous Chondrocyte Implantation) were used by several authors since their first use [26] in 1998. This technique (Chondrogide $\bigotimes$ ) uses a matrix of synthetic, porcine origin of collagen types I and III membranes. Behrens [35] first reported encouraging results in 2006 even if the series contains few cases ( 5 knees with 5 years follow-up). Other studies show that an International Knee Documentation Committee (IKDC) score significantly improved after 6 months with a transplant type MACI Chondrogide $\nabla[36]$ extends to 3 years in $80 \%$ of cases. On the other hand, a low improvement 6 months after the surgery ended in failure in 1 case out of 2 . Macmull [37] showed that the results

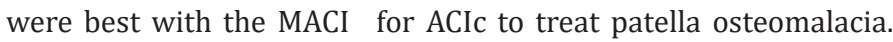
Salzmann [38] showed the superiority of the MACIه OATS in a small number of cases.
Filardo [39] evaluates 133 knees treated with another type of ACI 2nd generation: Hyalograft C $\otimes$ (benzyl ester of hyaluronan) embedded with chondrocytes cultured [40] and then implanted. The results provide factors predictive of the best clinical outcomes. When the lesion was recent, small, traumatic or secondary to an osteochondritis dissecans of the condyle, in a young man and without prior surgery, results were better. It would also seem that the transplant of the trochlea gives better results than the transplants to other regions of the knee [41] for 2nd generation transplants. The MACT ACI-Maix区 (Matricel GmbH, Germany) are also a matrix of collagen types I and III [42]. Their use is suitable for patients of less than 60 with "OA" lesions started after to Bauer [43]. Indeed, it reported satisfactory clinical results 5 years post-transplant, but the relevance of this type of MACI evaluation is delicate. Indeed, Meyerkort [44] and Bauer [43] evaluated patients many of whom had undergone an associated surgical procedure (valgisation, translation of the tibial tuberosity) and responsibility of chondrocytes transplantation whether they had experienced clinical improvement is difficult to say.

Furthermore Ebert [45] showed that 5 years after MACI surgery, the correlation between clinical score (KOOS) and imaging was very limited making the relevance of these evaluations sometimes random. Saris [46] report in a multicentric study of level I, a significant improvement in pain and function of the knee after 2 years for at least $3 \mathrm{~cm}^{2}$ in the case of MACI $\square$ compared to micro-lesions frac-

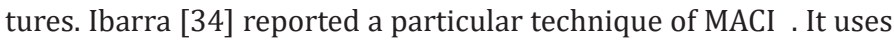
a membrane of PGFLA to encapsulate [47] chondrocytes, cultivated and seeded on a porcine matrix of collagen I and III. This technique seems to prevent the escape of cells in the joint during surgery and can be undertaken exclusive arthroscopically. Clinical improvement and integration of the transplant can be seen on MRI, 3 years after surgery on 10 patients [34], but the average size of the lesion was only $1 \mathrm{~cm}^{2}$. CaReS $\bigotimes$ is another type I collagen tissue which present like 3D gel with embedded chondrocytes. This method compared to microfractures [48] to treat patello-femoral cartilage injury, under $3 \mathrm{~cm}^{2}$ and with 3 years follow-up, showed a clinical improvement with CaReS $\otimes$ but no significant difference between the groups.

Zellner [49] reported the use of the NOVOCART 3DQ (bilayer matrix of collagen and chondroïtine sulfate) in a study which evaluates both histologically and clinically. The IKDC score is upgraded to one year of follow-up in patients treated for lesions of average size of $5 \mathrm{~cm} 2$ and level II, III or IV according the ICRS. The author insists on the need for favourable conditions for the survival and differentiation of chondrocytes that creates the matrix bilayer (a porous layer of collagen for the incorporation of chondrocytes and the other layer, dense in bovine pericardium for adhesion to the injured area). The production of type II collagen and cells live/dead ratio would be good prognosis for transplants performed in these patients. Niethammer [50] who used NOVOCART 3D $\nabla$ evokes just the same graft hypertrophies but these complications are significantly more common if the initial ethology of injury is due to a loss of recent traumatic substance or an osteochondritis dissecans.

Filardo [51] reported 44 patients with cartilage damage with radiological osteoarthritis (Kellgren 2 or 3 ) treated with second 


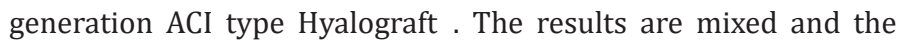
author evokes a negative joint environment in these patients already badly affected by osteoarthritis. The existence of radiological osteoarthritis appears clearly to be a limiting factor in the use of these cartilage transplants. Yet Schinhan [52] had suggested the

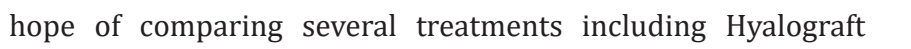
stocked with chondrocytes with other therapies to treat a cartilage lesion with radiological osteoarthritis established. The results were better with the ACI but it was however an animal model. Könst [53] reports his experience of the use of the Chondron区 (suspension of cultured chondrocytes in three-dimensional fibrin gel) for cases of damaged osteochondrals requiring transplantation of the spongy material underlying the bone. The practical aspect is here clearly established that due to the primary adhesion but the follow-up ( 9 months) is too low for judging the effectiveness on the cartilaginous integration and the final nature of the fabric.

Selmi [32] published good results for 13 patients with cartilage damage, 2,7 cm凶 average, treated by ACI embedded in Cartipatch $\otimes$ (alginate and algarose solid matrix). It seems that biggest and deeper is the lesion the better results are. The results were not significant and this technic is not available, because it is too expensive. ACl's 2 nd generation offers the theoretical advantage of a seeding of the structure transplanted by cultured chondrocytes, but also to fulfil the treated lesion (with the use of fabrics in 3D). The results are generally good and superior [54] to other techniques (ACIp, microfractures). However the follow-up is low and the extra cost is not yet offset by a significant improvement. Yet, Vijayan [55] is in favour of the use of these 2 nd generation transplants of chondrocytes. It shows indeed that the surgical recovery after failure of the ACI or MACI is still possible by a new graft without resorting to arthroplasty and knee joint function is maintained. In a multcentric

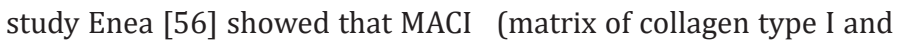
III) allows the development of a hyaline cartilage approximating normal tissue in most cases. Yet, the author recommends to use the adage 'hyaline cartilage = decrease in symptoms' carefully because it was unable to be highlighted in his series.

It is possible to transplant the chondrocytes in time without culture. The CAIS $\square$ (Cartilage Autograft Implantation System, Depuy Mitek Inc.) and deNovo NT囚 (Zimmer, Inc.) are techniques developed recently [57,58]. CAIS $₫[58]$ which require chondrocytes from the knee in the healthy zone; cartilage chips are then scattered over the absorbable matrix of copolymers composed of $65 \%$ of polycaprolactone (PCL), 35\% of polyglycolic acid (PGA) and reinforced by a lattice of polydioxanone (PDS). For deNovo NT区, pieces of cartilage from adolescents have been used. This is an allograft included in a matrix and adhered with biological glue (fibrin glue). Farr [59] reported 25 cases with good integration and significant clinical improvement. However this technic is not exportable in all countries because it is allograft and its ranking within the $\mathrm{ACI}$ remains ambiguous. Moreover follow-up are minor and few in numbers.

\section{c) Third generation: C3G}

The same criticism can be seen by reading the article of Crawford [60] that the use of NeoCart $\bigotimes$ for 8 patients whose clinical out- come and MRI after 2 years seems reliable. It is a matrix of bovine collagen type I seeded by chondrocytes cultivated and prepared in a bioreactor. The techniques described below constitute the ACI's 3rd generation which according to Harris [3] are defined by a procedure with 1 or 2 surgical steps but especially by chondrocytes cultured and implanted in a three-dimensional matrix 'chondro-inductive and conductive chondro'. There is a few studies reported in the literature about ACI 3G. If the difference between transplantation of chondrocytes of first and second generation is clear in the literature that between the second and third generations is much less. For Versier [61] and Basad [62] the principle of 2nd generation transplants is to replace only the periosteum by an artificial membrane; Brittberg [63] and Goyal [64] gave the same explanation for the difference between the first and second generations of grafts. However they consider that 3rd generation transplants use a carrier in order to be better integrated into the lesion.

Harris [3] in a review of failures after chondrocytes transplant clarifies the situation. For him second generation are defined by a surgical procedure in 2 steps with implantation of chondrocytes cultured on a bioabsorbable structured matrix, plane or tridimensionnal. For transplants of the third generation, the difference lies in the level of support of chondrocytes because the matrix is in 3D, chondro-inductive and chondro-driver. Kon [65] in a review of the latest transplantation techniques does not distinguish between the second and third generation. For the author, C2G and C3G techniques are grouped under a single entity MACT. This lack of distinction seems more logical because the main difference between the first generation (ACIC and ACIp) and the other is that grown chondrocytes are not covered up a membrane for the transplantation but taken by a matrix vector, regardless of its composition.

\section{d) Transplantation of Mesenchymal stem Cells}

The Mesenchymal Stems Cells (MSC) has been used for a few years and in one way represents the future for chondrocyte transplants. Wakitani [66] reported in 2007 a first experience with transplantation of MSC under a flap. Clinical improvement has been proven in 3 cases to the maximum follow-up in 27 months. This same author [67] reported that these transplants of MSC are without negative effects even at the maximum 11-year deterioration for a cohort of 45 knees. However, Nejadnik [68] provides no evidence of improvement two years after surgery of MSC grafts compared to the first generation (ACI). It use of MSC is justified by requiring less anesthesia (sampling at the level of the iliac crest), less cartilage aggression in the knee because healthy cartilage is not taken and a lower cost of the technique because of no need for culture of chondrocytes. Grafts were however performed with a periosteal flap to prevent the escape of the cells. Mazor and coll [69] showed in a recent review the benefits of the MSC to repair the cartilage but for now MSC transplants under a membrane of synthesis of collagen or within a matrix have never been reported in clinical practice.

\section{Conclusion}

This literature review allowed us to update all of the available scientific information on the surgical treatment of cartilage lesions with cellular therapy. It is always difficult to assert the superiority 
of one technique over another. For example Negrín [70] reviews in a meta-analysis all the releases that compared the microfractures with ACI of all generations and found no clinical superiority of one technique over another. In addition, compared treatments are not always applied to the same regions of the knee. Sometimes complementary actions, such as osteotomies or ACL plasty, are made and it is not certain that the evaluation of the tested technique is relevant. Variations in methods of evaluation are complex comparisons. Some work is mainly focussed on the clinical and functional outcome of the patient while others observe histological changes and imaging. For example, conventional MRI does not reliably assess cartilage after surgery. The evaluation of the mechanical axes of the lower limbs, as well as knee ligament stability is prerequisites to any support surgical cartilage pathologies.

The main problems encountered during a 1st generation chondrocytes transplant are cartilage hypertrophy, the healing of the area registered in the form of a fibro cartilage rather than hyaline cartilage, the delamination of the fabric and intra articular adherence [71]. The structural environment and the accession of chondrocytes were considered the major problems to be resolved to improve the results of transplantation of chondrocytes. Chondrocyte transplants have evolved for 20 years but still present the disadvantages of high cost, the need for a cartilage assault to remove chondrocytes to cultivate and often a two stage surgical procedure. Further comparison of the different generations of chondrocyte transplants collides with variations in naming between the different generations in the literature. Transplantation of cultivated chondrocytes and seeded on a matrix in 3 dimensions appear as by far the most accomplished technique for the treatment of the large cartilage lesions. It appears clearly that lesions treated will get a much better result if the patient is younger, if the duration of the symptoms is short or if the patient has never been operated on.

\section{References}

1. Becerra J, Andrades JA, Guerado E, Zamora-Navas P, López-Puertas JM, et al. (2010) Articular cartilage: structure and regeneration. Tissue Eng Part B Rev 16(6): 617-627.

2. Brittberg M, Lindahl A, Nilsson A, Ohlsson C, Isaksson O, et al. (1994) Treatment of deep cartilage defects in the knee with autologous chondrocyte transplantation. N Engl J Med 331(14): 889-895.

3. Harris JD, Siston RA, Brophy RH, Lattermann C, Carey JL, et al. (2011) Failures, re-operations, and complications after autologous chondrocyte implantation--a systematic review. Osteoarthritis Cartilage 19(7): 779791.

4. Viste A, Piperno M, Desmarchelier R, Grosclaude S, Moyen B, et al. (2012) Autologous chondrocyte implantation for traumatic full-thickness cartilage defects of the knee in 14 patients: 6-year functional outcomes. Orthop Traumatol Surg Res 98(7): 737-743.

5. Peterson L, Vasiliadis HS, Brittberg M, Lindahl A (2010) Autologous chondrocyte implantation: a long-term follow-up. Am J Sports Med 38(6): 1117-1124.

6. Moradi B, Schönit E, Nierhoff C, Hagmann S, Oberle D, et al. (2012) First-generation autologous chondrocyte implantation in patients with cartilage defects of the knee: 7 to 14 years' clinical and magnetic resonance imaging follow-up evaluation. Arthroscopy 28(12): 18511861.

7. Horas U, Pelinkovic D, Herr G, Aigner T, Schnettler R (2003) Autologous chondrocyte implantation and osteochondral cylinder transplantation in cartilage repair of the knee joint. A prospective, comparative trial. J Bone Joint Surg Am 85-A(2): 185-192.

8. Bentley G, Biant LC, Vijayan S, Macmull S, Skinner JA, et al. (2012) Minimum ten-year results of a prospective randomised study of autologous chondrocyte implantation versus mosaicplasty for symptomatic articular cartilage lesions of the knee. J Bone Joint Surg Br 94(4): 504-509.

9. Knutsen G, Drogset JO, Engebretsen L, Grøntvedt T, Isaksen V, et al. (2007) A randomized trial comparing autologous chondrocyte implantation with microfracture. Findings at five years. J Bone Joint Surg Am 89(10): 2105-2012.

10. Pestka JM, Bode G, Salzmann G, Südkamp NP, Niemeyer P (2012) Clinical outcome of autologous chondrocyte implantation for failed microfracture treatment of full-thickness cartilage defects of the knee joint. Am J Sports Med 40(2): 325-331.

11. Minas T, Gomoll AH, Rosenberger R, Royce RO, Bryant T (2009) Increased failure rate of autologous chondrocyte implantation after previous treatment with marrow stimulation techniques. Am J Sports Med 37(5): 902-908.

12. Minas T, Von Keudell A, Bryant T, Gomoll AH (2014) The John Insall Award: A minimum 10-year outcome study of autologous chondrocyte implantation. Clin Orthop Relat Res 472(1): 41-51.

13. Niemeyer P, Köstler W, Salzmann GM, Lenz P, Kreuz PC, et al. (2010) Autologous chondrocyte implantation for treatment of focal cartilage defects in patients age 40 years and older: A matched-pair analysis with 2-year follow-up. Am J Sports Med 38(12): 2410-2416.

14. Rosenberger RE, Gomoll AH, Bryant T, Minas T (2008) Repair of large chondral defects of the knee with autologous chondrocyte implantation in patients 45 years or older. Am J Sports Med, 2008. 36(12): 2336-2344.

15. Gillogly SD, RM Arnold (2014) Autologous chondrocyte implantation and anteromedialization for isolated patellar articular cartilage lesions: 5- to 11-year follow-up. Am J Sports Med 42(4): 912-920.

16. Trinh TQ, Harris JD, Siston RA, Flanigan DC (2013) Improved outcomes with combined autologous chondrocyte implantation and patellofemoral osteotomy versus isolated autologous chondrocyte implantation. Arthroscopy 29(3): 566-574.

17. Kreuz PC, Müller S, von Keudell A, Tischer T, Kaps C, et al. (2013) Influence of sex on the outcome of autologous chondrocyte implantation in chondral defects of the knee. Am J Sports Med 41(7): 1541-1548.

18. Gooding CR, Bartlett W, Bentley G, Skinner JA, Carrington R, et al. (2006) A prospective, randomised study comparing two techniques of autologous chondrocyte implantation for osteochondral defects in the knee: Periosteum covered versus type I/III collagen covered. Knee 13(3): 203-210.

19. Samuelson EM, DE Brown (2012) Cost-effectiveness analysis of autologous chondrocyte implantation: a comparison of periosteal patch versus type I/III collagen membrane. Am J Sports Med 40(6): 12521258.

20. Pietschmann MF, Niethammer TR, Horng A, Gülecyüz MF, FeistPagenstert I, et al. (2012) The incidence and clinical relevance of graft hypertrophy after matrix-based autologous chondrocyte implantation. Am J Sports Med 40(1): 68-74.

21. Dellaccio F, C De Bari, FP Luyten (2001) Molecular markers predictive of the capacity of expanded human articular chondrocytes to form stable cartilage in vivo. Arthritis Rheum 44(7): 1608-1619.

22. Saris DB, Vanlauwe J, Victor J, Almqvist KF, Verdonk R, et al. (2009) Treatment of symptomatic cartilage defects of the knee: characterized chondrocyte implantation results in better clinical outcome at 36 months in a randomized trial compared to microfracture. Am J Sports Med 37(Suppl 1): 10S-19S.

23. Vanlauwe J, Saris DB, Victor J, Almqvist KF, Bellemans J, et al. (2011) Five-year outcome of characterized chondrocyte implantation versus 
microfracture for symptomatic cartilage defects of the knee: early treatment matters. Am J Sports Med 39(12): 2566-2574.

24. Kon E, Delcogliano M, Filardo G, Montaperto C, Marcacci M (2008) Second generation issues in cartilage repair. Sports Med Arthrosc 16(4): 221-229.

25. Grigolo B, Lisignoli G, Piacentini A, Fiorini M, Gobbi P, etal. (2002) Evidence for redifferentiation of human chondrocytes grown on a hyaluronanbased biomaterial (HYAff 11): molecular, immunohistochemical and ultrastructural analysis. Biomaterials 23(4): 1187-1195.

26. Behrens P, Ehlers EM, Köchermann KU, Rohwedel J, Russlies M, et al. (1999) New therapy procedure for localized cartilage defects. Encouraging results with autologous chondrocyte implantation. MMW Fortschr Med 141(45): 49-51.

27. Schneider U, Rackwitz L, Andereya S, Siebenlist S, Fensky F, et al. (2011) A prospective multicenter study on the outcome of type I collagen hydrogel-based autologous chondrocyte implantation (CaReS) for the repair of articular cartilage defects in the knee. Am J Sports Med 39(12) 2558-2565.

28. Ossendorf C, Kaps C, Kreuz PC, Burmester GR, Sittinger M, et al. (2007) Treatment of posttraumatic and focal osteoarthritic cartilage defects of the knee with autologous polymer-based three-dimensional chondrocyte grafts: 2-year clinical results. Arthritis Res Ther 9(2): R41.

29. Zak L, Albrecht C, Wondrasch B, Widhalm H, Vekszler G, et al. (2014) Results 2 Years After Matrix-Associated Autologous Chondrocyte Transplantation Using the Novocart 3D Scaffold: An Analysis of Clinical and Radiological Data. Am J Sports Med 42(7): 1618-1627.

30. Visna P, Pasa L, Cizmár I, Hart R, Hoch J, et al. (2004) Treatment of deep cartilage defects of the knee using autologous chondrograft transplantation and by abrasive techniques--a randomized controlled study. Acta Chir Belg 104(6): 709-714.

31. Choi NY, Kim BW, Yeo WJ, Kim HB, Suh DS, et al. (2010) Gel-type autologous chondrssocyte (Chondron) implantation for treatment of articular cartilage defects of the knee. BMC Musculoskelet Disord 11 103.

32. Selmi TA, Verdonk P, Chambat P, Dubrana F, Potel JF, et al. (2008) Autologous chondrocyte implantation in a novel alginate-agarose hydrogel: outcome at two years. J Bone Joint Surg Br 90(5): 597-604.

33. Brix MO, Stelzeneder D, Chiari C, Koller U, Nehrer S, et al. (2014) Treatment of Full-Thickness Chondral Defects With Hyalograft C in the Knee: Long-term Results. Am J Sports Med 42(6): 1426-1432.

34. Ibarra C, Izaguirre A, Villalobos E, Masri M, Lombardero G, et al. (2014) Follow-up of a new arthroscopic technique for implantation of matrixencapsulated autologous chondrocytes in the knee. Arthroscopy 30(6): 715-723.

35. Behrens P, Bitter T, Kurz B, Russlies M (2006) Matrix-associated autologous chondrocyte transplantation/implantation (MACT/MACI)-5-year follow-up. Knee 13(3): 194-202.

36. Pestka JM, Bode G, Salzmann G, Steinwachs M, Schmal H, et al. (2014) Clinical outcomes after cell-seeded autologous chondrocyte implantation of the knee: when can success or failure be predicted? Am J Sports Med 42(1): 208-215.

37. Macmull S, Jaiswal PK, Bentley G, Skinner JA, Carrington RW, et al. (2012) The role of autologous chondrocyte implantation in the treatment of symptomatic chondromalacia patellae. Int Orthop 36(7): 1371-1377.

38. Salzmann GM, Paul J, Bauer JS, Woertler K, Sauerschnig M, et al. (2009) T2 assessment and clinical outcome following autologous matrixassisted chondrocyte and osteochondral autograft transplantation. Osteoarthritis Cartilage 17(12): 1576-1582.

39. Filardo G, Kon E, Andriolo L, Di Matteo B, Balboni F, et al. (2014) Clinical profiling in cartilage regeneration: prognostic factors for midterm results of matrix-assisted autologous chondrocyte transplantation. Am J Sports Med 42(4): 898-905.
40. Marcacci M, Zaffagnini S, Kon E, Visani A, Iacono F, et al. (2002) Arthroscopic autologous chondrocyte transplantation: technical note. Knee Surg Sports Traumatol Arthrosc 10(3): 154-159.

41. Filardo G, Kon E, Andriolo L, Di Martino A, Zaffagnini S, et al. (2014) Treatment of "patellofemoral" cartilage lesions with matrix-assisted autologous chondrocyte transplantation: a comparison of patellar and trochlear lesions. Am J Sports Med 42(3): 626-634.

42. Zheng MH, Willers C, Kirilak L, Yates P, Xu J, et al. (2007) Matrix-induced autologous chondrocyte implantation (MACI): biological and histological assessment. Tissue Eng 13(4): 737-746.

43. Bauer S, Khan RJ, Ebert JR, Robertson WB, Breidahl W, et al. (2012) Knee joint preservation with combined neutralising high tibial osteotomy (HTO) and Matrix-induced Autologous Chondrocyte Implantation (MACI) in younger patients with medial knee osteoarthritis: a case series with prospective clinical and MRI follow-up over 5 years. Knee 19(4): 431-439.

44. Meyerkort D, Ebert JR, Ackland TR, Robertson WB, Fallon M, et al. (2014) Matrix-induced autologous chondrocyte implantation (MACI) for chondral defects in the patellofemoral joint. Knee Surg Sports Traumatol Arthrosc 22(10): 2522-2530.

45. Ebert JR, Smith A2, Fallon M3, Wood DJ4, Ackland TR (2014) Correlation Between Clinical and Radiological Outcomes After Matrix-Induced Autologous Chondrocyte Implantation in the Femoral Condyles. Am J Sports Med 42(8): 1857-1864.

46. Saris D, Price A, Widuchowski W, Bertrand-Marchand M, Caron J, et al. (2014) Matrix-Applied Characterized Autologous Cultured Chondrocytes Versus Microfracture: Two-Year Follow-up of a Prospective Randomized Trial. Am J Sports Med 42(6): 1384-1394.

47. Masri M, Lombardero G, Velasquillo C, Martínez V, Neri R, et al. (2007) Matrix-encapsulation cell-seeding technique to prevent cell detachment during arthroscopic implantation of matrix-induced autologous chondrocytes. Arthroscopy 23(8): 877-883.

48. Petri M, Broese M, Simon A, Liodakis E, Ettinger M, et al. (2013) CaReS (MACT) versus microfracture in treating symptomatic patellofemoral cartilage defects: a retrospective matched-pair analysis. J Orthop Sci 18(1): 38-44.

49. Zellner J, Angele P, Zeman F, Kujat R, Nerlich M (2013) Is the transplant quality at the time of surgery adequate for matrix-guided autologous cartilage transplantation? A pilot study. Clin Orthop Relat Res 471(9): 2852-2861.

50. Niethammer TR, Pietschmann MF, Horng A, Roßbach BP, Ficklscherer A, et al. (2014) Graft hypertrophy of matrix-based autologous chondrocyte implantation: a two-year follow-up study of NOVOCART 3D implantation in the knee. Knee Surg Sports Traumatol Arthrosc 22(6): 1329-1336.

51. Filardo G, Vannini F, Marcacci M, Andriolo L, Ferruzzi A, et al. (2013) Matrix-assisted autologous chondrocyte transplantation for cartilage regeneration in osteoarthritic knees: results and failures at midterm follow-up. Am J Sports Med 41(1): 95-100.

52. Schinhan M, Gruber M, Dorotka R, Pilz M, Stelzeneder D, et al. (2013) Matrix-associated autologous chondrocyte transplantation in a compartmentalized early stage of osteoarthritis. Osteoarthritis Cartilage 21(1): 217-225.

53. Konst YE, Benink RJ, Veldstra R, van der Krieke TJ, Helder MN, et al. (2012) Treatment of severe osteochondral defects of the knee by combined autologous bone grafting and autologous chondrocyte implantation using fibrin gel. Knee Surg Sports Traumatol Arthrosc 20(11): 2263-2269.

54.Zeifang F, Oberle D, Nierhoff C, Richter W, Moradi B, et al. (2010) Autologous chondrocyte implantation using the original periosteumcover technique versus matrix-associated autologous chondrocyte implantation: a randomized clinical trial. Am J Sports Med 38(5): 924933. 
55. Vijayan S, Bentley G, Rahman J, Briggs TW, Skinner JA, et al. (2014) Revision cartilage cell transplantation for failed autologous chondrocyte transplantation in chronic osteochondral defects of the knee. Bone Joint J 96-B(1): 54-58.

56. Enea D, Cecconi S, Busilacchi A, Manzotti S, Gesuita R, et al. (2012) Matrix-induced autologous chondrocyte implantation (MACI) in the knee. Knee Surg Sports Traumatol Arthrosc 20(5): 862-869.

57. Farr J, Cole BJ, Sherman S, Karas V (2012) Particulated articular cartilage: CAIS and DeNovo NT. J Knee Surg 25(1): 23-29.

58. McCormick F, Yanke A, Provencher MT, Cole BJ (2008) Minced articular cartilage--basic science, surgical technique, and clinical application. Sports Med Arthrosc 16(4): 217-220.

59. Farr J, Tabet SK, Margerrison E, Cole BJ (2014) Clinical, Radiographic, and Histological Outcomes After Cartilage Repair With Particulated Juvenile Articular Cartilage: A 2-Year Prospective Study. Am J Sports Med 42(6): 1417-1425.

60. Crawford DC, Heveran CM, Cannon WD, Foo LF, Potter HG (2009) An autologous cartilage tissue implant NeoCart for treatment of grade III chondral injury to the distal femur: prospective clinical safety trial at 2 years. Am J Sports Med 37(7): 1334-1343.

61. Versier G, Dubrana F, S. French Arthroscopy Society (2011) Treatment of knee cartilage defect in 2010. Orthop Traumatol Surg Res 97(8 Suppl): S140-S153.

62. Basad E, Ishaque B, Bachmann G, Stürz H, Steinmeyer J (2010) Matrixinduced autologous chondrocyte implantation versus microfracture in the treatment of cartilage defects of the knee: a 2-year randomised study. Knee Surg Sports Traumatol Arthrosc 18(4): 519-527.

63. Brittberg M (2010) Cell carriers as the next generation of cell therapy for cartilage repair: a review of the matrix-induced autologous chondrocyte implantation procedure. Am J Sports Med 38(6): 1259-1271.
64. Goyal D, Goyal A, Keyhani S, Lee EH, Hui JH (2013) Evidence-based status of second- and third-generation autologous chondrocyte implantation over first generation: a systematic review of level I and II studies. Arthroscopy 29(11): 1872-1878.

65. Kon E, Filardo G, Di Matteo B, Perdisa F, Marcacci M (2013) Matrix assisted autologous chondrocyte transplantation for cartilage treatment: A systematic review. Bone Joint Res 2(2): 18-25.

66. Wakitani S, Nawata M, Tensho K, Okabe T, Machida H, et al. (2007) Repair of articular cartilage defects in the patello-femoral joint with autologous bone marrow mesenchymal cell transplantation: three case reports involving nine defects in five knees. J Tissue Eng Regen Med 1(1): 74-79.

67. Wakitani S, Okabe T, Horibe S, Mitsuoka T, Saito M, et al. (2011) Safety of autologous bone marrow-derived mesenchymal stem cell transplantation for cartilage repair in 41 patients with 45 joints followed for up to 11 years and 5 months. J Tissue Eng Regen Med 5(2): 146-150.

68. Nejadnik H, Hui JH, Feng Choong EP, Tai BC, Lee EH (2010) Autologous bone marrow-derived mesenchymal stem cells versus autologous chondrocyte implantation: an observational cohort study. Am J Sports Med 38(6): 1110-1116.

69. Mazor M, Lespessailles E, Coursier R, Daniellou R, Best TM, et al. (2014) Mesenchymal stem-cell potential in cartilage repair: an update. J Cell Mol Med 18(12): 2340-2350.

70. Negrin LL, V Vecsei (2013) Do meta-analyses reveal time-dependent differences between the clinical outcomes achieved by microfracture and autologous chondrocyte implantation in the treatment of cartilage defects of the knee? J Orthop Sci 18(6): 940-948.

71. Peterson L, Minas T, Brittberg M, Nilsson A, Sjögren-Jansson E, et al. (2000) Two- to 9-year outcome after autologous chondrocyte transplantation of the knee. Clin Orthop Relat Res (374): 212-234.

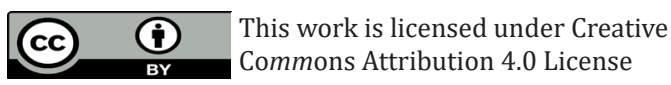

Submission Link: https://biomedres.us/submit-manuscript.php

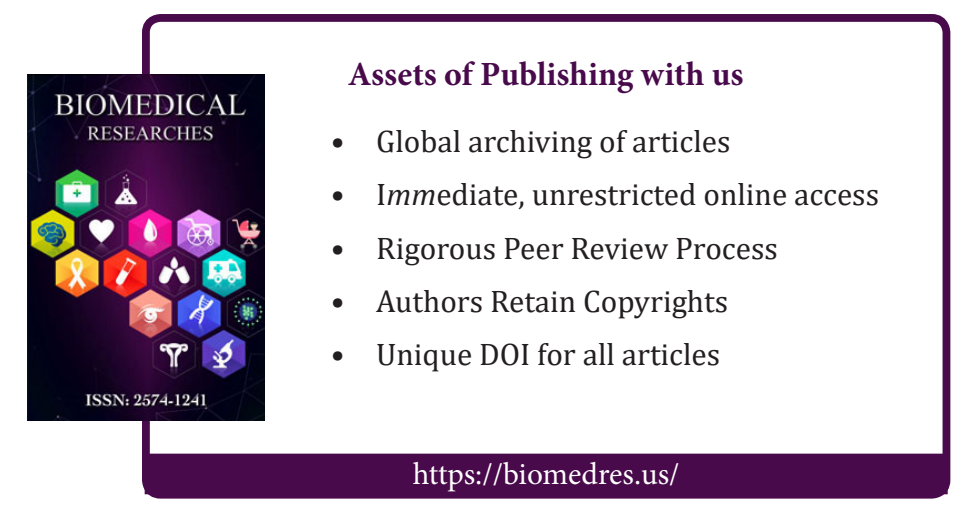

